\title{
O INCONSCIENTE DEPOIS DE LACAN: TEMPORALIDADE E SIGNIFICAÇÃO
}

\author{
The Unconscious after Lacan: \\ temporality and signification
}

Suely Aires Pontes ${ }^{1}$

\section{Resumo}

Neste artigo, proponho apresentar a concepção de inconsciente formulada por Jacques Lacan, tendo como apoio as críticas de Georges Politzer à teoria freudiana, mais especificamente as alterações em torno da temporalidade do inconsciente e da significação dos ditos dos analisantes.

Palavras-chave: Inconsciente; Psicanálise; Freud; Lacan; Politzer.

\section{Abstract}

This article is aimed to present the conception of unconscious proposed by Jacques Lacan using the Politzer's criticism to the freudian theory, mostly conceming the modifications of unconscious temporality and the signification of the analisants' speech.

Keywords: Unconscious; Psychoanalysis; Freud; Lacan; Politzer.

1 Doutoranda Fil-Unicamp. Campinas - SP. End.: Rua Antonio Bertho, 70 - Jardim Santa Genebra Campinas - SP - CEP: 13.080-120

Tel.: (19) 3208.1099 - (19) 9123.8703. E-mail: suely.aires@uol.com.br

Revista de Filosofia, Curitiba, v. 17 n.20, p. 165-184, jan./jun. 2005. 


\section{Introdução}

O inconsciente é freqüentemente considerado como o conceito princeps da psicanálise, não apenas por seu valor diferencial em relação a outras teorias do psiquismo, mas também devido à importância dada por Freud a ele na construção da teoria. No entanto, há grandes divergências quanto à significação e extensão daquilo que se entende por inconsciente. As modificações propostas por Jacques Lacan ao apresentar o inconsciente estruturado como linguagem, mais especificamente referentes ao período de 1953-1966, apontam para uma concepção de temporalidade inconsciente, bem como de significação dos conteúdos proferidos pelo analisante que não se deixam subsumir às formulações freudianas sobre o tema. Neste artigo, proponho apresentar a concepção lacaniana de inconsciente, tendo como contraponto as formulações freudianas sobre o conceito e como base de análise as críticas proferidas por Politzer em Critique des Fondements de la Psychologie.

\section{O inconsciente freudiano}

A construção freudiana da noção de inconsciente segue um longo percurso, o qual será apresentado de forma resumida neste tópico, dadas as limitações de um artigo. As primeiras conceituações freudianas sobre o inconsciente surgem em Estudos sobre a Histeria (1895) quando, antes de sua acepção como sistema psíquico, o inconsciente era utilizado apenas em sentido adjetivo ou adverbial. O uso substantivo do conceito - que aparece de forma muito rara neste momento - surge como uma primeira modificação de linguagem feita por Freud que visa a constituição de uma terminologia própria à psicanálise. Neste momento de sua teorização, o inconsciente é relacionado com pressentimentos (sic) negativos que surgem na fala de uma paciente, Frau Emmy von. N, os quais antecipam o reaparecimento de determinados sintomas. Para Freud, tais pressentimentos podem ser considerados como indicadores de um estado que já estava em elaboração e que foi percebido inconscientemente, relacionando-se, portanto, com as lacunas e ligações falsas características do funcionamento histérico.

Revista de Filosofia, Curitiba, v. 17 n.20, p. 165-184, jan./jun. 2005. 
A substantivação do termo inconsciente ganha amplitude depois de 1900, em A Interpretação dos Sonhos, quando a suposição da existência de impulsos impregnados de desejo - fundamento necessário para uma equivalência entre o procedimento psicanalítico de interpretação dos sonhos e o método para solucionar sintomas histéricos - toma como apoio a noção de inconsciente, lugar psíquico em que esses impulsos ficam retidos enquanto não conseguem expressão. Esse argumento conduz simultaneamente a dois problemas: (1) a substancialização dos processos psíquicos e (2) a espacialização do inconsciente como interioridade. Ambos os problemas decorrem do uso freudiano de uma mesma linguagem para se referir a objetos físicos e objetos mentais, de modo que ela acaba por desconsiderar as diferenças categoriais em jogo. Esse afastamento da linguagem ordinária por meio da substantivação pode vir a gerar confusões, pois parece indicar a denotação de algo com existência real.

Se o início da confusão entre empírico e conceitual se dá pela terminologia utilizada, sua ampliação se deve ao ideal de cientificidade de Freud. Ao tomar a física como ideal de ciência, Freud se preocupa em validar empiricamente as construções psicanalíticas e apresenta interpretações como se fossem explicações, reivindicando o caráter de descoberta científica à descrição realizada. Na perspectiva freudiana, a ciência surge como tradução ou afiguração de uma realidade efetiva, de modo que parece se tratar de um mesmo conteúdo apresentado em versões distintas. Por conseguinte, Freud pode supor a linguagem figurada da psicanálise - suas famosas analogias e metáforas - como formas mitológicas necessárias para descrever os processos psíquicos, inabordáveis sem tais recursos. Cabe destacar que, por ser um fiel defensor da ciência como forma máxima e mais elaborada do pensamento humano, Freud busca inscrever a psicanálise no campo das ciências de sua época, por um lado, construindo uma teoria de caráter explicativo e, por outro, evitando uma aproximação entre a psicanálise e a religião ou a filosofia.

Em 1915 Freud busca justificar a criação do conceito de inconsciente e a validade da aplicação dessa noção para referir-se a uma instância psíquica possuidora de características próprias. Na obra O Inconsciente a hipótese conceitual freudiana é apresentada como necessária para o esclarecimento de um dado campo da experiência psicanalítica: as lacunas no relato dos pacientes quando estes se referem a seus sonhos ou sintomas. No entanto, ao longo do texto, estas lacunas do relato são

Revista de Filosofia, Curitiba, v. 17 n.20, p. 165-184, jan./jun. 2005. 
simultaneamente apresentadas como dados colhidos na experiência analítica e como provas empíricas da existência do sistema inconsciente. Por conseguinte, a hipótese freudiana do inconsciente se torna irrefutável e ganha a aparência de uma descoberta empírica. Nesta obra, quando propõe a construção de um aparelho mental composto por diversos sistemas psíquicos - que toma como modelo a neurologia e suas estruturas materiais - Freud traz para o seio da psicanálise a problemática relativa à substancialização e espacialização do inconsciente.

A hipótese freudiana de um uso sistêmico do termo 'inconsciente', tal como proposta desde 1900, apóia-se sobre três pontos básicos: (1) o reconhecimento da existência de processos mentais inconscientes que Freud vincula às lacunas no relato individual, (2) a refutação da equivalência entre psíquico e consciente - associada às ligações falsas como desconhecimento consciente das motivações individuais - e, (3) por inferência, a revelação de um sistema psíquico desconhecido do sujeito. Cabe ressaltar que a proposta freudiana de supor um aparelho psíquico composto por sistemas tem fundamental importância argumentativa em sua obra por determinar as características diferenciais dos diversos processos psíquicos, já que cada sistema está submetido a leis próprias de funcionamento. Desse modo, as diferenças entre os processos psíquicos não seriam meramente conceituais, mas seriam explicadas pela pertença a um sistema psíquico. Para que o sentido sistêmico do termo inconsciente seja diferenciado do uso descritivo é necessário ter claro que, no primeiro caso, implica a inclusão de processos psíquicos em uma instância particular possuidora de características específicas. Poderíamos dizer, para exemplificar, que uma idéia inconsciente topograficamente localizada no pré-consciente pode aceder à consciência a qualquer momento - trata-se de uma idéia latente. Já um processo psíquico topograficamente localizado no inconsciente está submetido a suas leis e é incapaz de tradução consciente - é um processo submetido ao recalque.

A relação entre topografia e espacialização precisa ser melhor esclarecida, pois não se mostra de modo tão simples. Embora na teoria psicanalítica, topografia psíquica não tenha qualquer tipo de relação com localização anatômica - pois a primeira refere-se a "regiões do mecanismo mental, onde quer que estejam situadas no corpo" (Freud, 1915) - a espacialização faz-se presente por meio da idéia de regiões, pressuposta na concepção de existência latente. Para Freud, como já destacamos

Revista de Filosofia, Curitiba, v. 17 n.20, p. 165-184, jan./jun. 2005. 
anteriormente, uma idéia latente está localizada em outro sistema que não a consciência. A justificativa de tal hipótese reside na crença freudiana de que um relato sempre atende a um referencial de coerência narrativa, cujas lacunas são subtrações de sentido. Desse modo, o sentido discursivo pode ser reencontrado se identificarmos os elementos faltantes para a lógica narrativa, elementos que se encontram ocultos em outro sistema psíquico, o inconsciente.

Outro aspecto relevante na associação entre topografia e espacialização é a linguagem utilizada. Além de uma descrição das características dos fenômenos psíquicos - no qual o uso adjetivo do termo inconsciente' seria suficiente - é apresentada uma explicação dessas características segundo sua localização sistêmica - quando o inconsciente aparece em seu caráter substantivo. Desse modo, duas formas distintas de abordar os fenômenos psíquicos são colocadas lado a lado, gerando uma confusão entre a formação de um conceito e a suposta explicação sobre o funcionamento de objetos pertencentes a um sistema. A exposição freudiana do inconsciente como instância psíquica detém-se sobre as características especiais às quais ficam submetidos os processos desse sistema - isenção de contradição mútua, atemporalidade, mobilidade dos investimentos e substituição da realidade externa pela psíquica.

A atemporalidade dos processos inconscientes baseia-se na idéia de uma isenção de contradição mútua. Ou seja, houve em algum momento da história do sujeito a inscrição de traços de memória que, por não terem relação entre si e por não terem qualquer referência ao tempo, tornaram-se inalteráveis. A idéia de inscrição psíquica, além de induzir a uma substancialização dos traços de memória, permite dizer que a temporalidade do inconsciente freudiano está associada ao tempo verbal do pretérito perfeito. Refere-se a uma ação já ocorrida que não pode mais ser modificada, que já foi inscrita. Ou seja, a atemporalidade diz respeito à relação entre os processos e destes com o 'mundo externo', mas a idéia de inscrição psíquica insere uma referência ao tempo já vivido.

A fim de explorar a questão sobre a temporalidade do inconsciente e suas implicações clínicas, tomarei uma analogia cara a Freud, a qual está presente em sua obra Construções em Análise (1937). Esta analogia consiste em comparar o trabalho do analista à escavação arqueológica por meio dos objetos em jogo nas referidas atividades: o objeto psíquico, "cuja história primitiva o analista está buscando recuperar"

Revista de Filosofia, Curitiba, v. 17 n.20, p. 165-184, jan./jun. 2005. 
(Freud, 1937) e o objeto arqueológico, destruído pelo saque ou pelo fogo. Na comparação entre esses objetos, Freud aponta uma diferença que lhe parece fundamental: os objetos psíquicos não sofrem a ação do tempo, mantendo preservados os elementos essenciais necessários ao trabalho do analista. Este tem por função trazer à luz o que está oculto. Pode-se argumentar que tal referência tem maior proximidade com a questão do método de investigação do que com a natureza do objeto, mas parece possível defender que tal método - escavação, descoberta e reconstrução - pressupõe certa materialidade dos conteúdos inconscientes, pois só é possível presumir que o trabalho analítico descobre a verdade oculta sob as deformações de conteúdo, se acreditarmos em um conteúdo 'soterrado', já existente e prévio à técnica de associação livre.

A proposta clínica freudiana parece estar diretamente relacionada ao conceito de inconsciente, o qual, como sistema psíquico, é articulado ao aparelho de memória, trazendo para a teoria a suposição de um lugar no qual os conteúdos ficam arquivados e cujo sentido foi dado no momento de sua inscrição como 'traço' no aparelho psíquico. $\mathrm{O}$ trabalho analítico, na perspectiva freudiana, consiste no uso da associação livre como meio de dar forma discursiva a idéias normalmente afastadas pelo paciente, as quais são consideradas como derivados de manifestações psíquicas recalcadas. Ao dar forma discursiva a essas idéias, o paciente, com a ajuda do analista, reconstrói a seqüência lógica de sua narrativa. Ou seja, baseado nas associações do paciente torna-se possível chegar ao material recalcado inconsciente por meio de deduções plausíveis, de modo que a técnica psicanalítica freudiana passa a funcionar como uma chave interpretativa para a resolução de conflitos neuróticos.

A técnica analítica, no entanto, não se constitui como uma prática introspectiva, mas como um relato induzido que rompe as barreiras do funcionamento consciente devido a sua articulação com a livre associação. A narrativa do paciente pode ser tomada como a descrição dos conteúdos que emergem quando o paciente volta a sua atenção sobre as próprias vivências buscando inseri-las numa ordem de sentido, sendo necessário que essa descrição seja feita para um outro. Por sua vez, o analista deve ouvir o relato sem, no entanto, sugerir ou proferir qualquer juízo moral quanto ao conteúdo da narrativa do paciente, pois não se trata da indução de uma dada forma de ver seu relato, mas do questionamento da ordem já dada, de modo a indicar os elementos faltantes para uma compreensão coerente e linear dos fatos.

Revista de Filosofia, Curitiba, v. 17 n.20, p. 165-184, jan./jun. 2005. 
Ao interpretar, o analista permite ao paciente descobrir a significação verdadeira de seu conflito e, dessa forma, encontrar uma solução. Por articular inconsciente e memória, Freud supõe que o tempo verbal do inconsciente seja o pretérito perfeito e, conseqüentemente, a prática interpretativa do analista teria por função revelar ou reencontrar os traços mnemônicos recalcados que dão sentido à lacuna do relato consciente. As aporias de um tal modo de conceber o inconsciente serão apontadas de modo claro pela crítica formulada por Politzer, tema de nosso próximo tópico, e prepararão o terreno para a discussão levantada por Lacan em torno da temporalidade do inconsciente.

\section{A Crítica Politzeriana}

A proposta politzeriana de uma crítica dos fundamentos da psicologia consiste em questionar o estatuto científico e filosófico do objeto da psicologia e criticar a impessoalidade dessa 'ciência', por meio da identificação dos pressupostos que mantêm a psicologia no campo das abstrações, não representativas do drama do agente particular. Apresentarei a seguir, de forma resumida, esses pressupostos em sua relação com a teoria freudiana.

A crença de que o psicológico é, em sua essência, algo elementar constitui-se no primeiro postulado da psicologia clássica. Esse pressuposto está ausente da teoria freudiana, pois, na concepção psicanalítica, a compreensão do fato psicológico - sonho ou sintoma - dá-se por meio dos referenciais da vida particular de um sujeito concreto. A psicanálise rompe com esse postulado ao abordar o psíquico como totalidade de vivências subjetivas.

O fato psicológico é um dado perceptivo é a segunda assertiva constituinte da psicologia clássica. A doutrina freudiana rompe com esse postulado ao afirmar que, para dar ao elemento psicológico seu lugar na totalidade, são necessárias mediações, já que o fato psicológico não é apreendido de forma imediata pela percepção, sendo interpretado pelo paciente em sua análise.

A terceira tese da psicologia clássica - a vida interior é uma reprodução da vida exterior - traz complicações para a doutrina freudiana, pois esta teoria faz uso de uma mesma gramática para se referir aos objetos do mundo externo e aos supostos objetos do mundo interno. A

Revista de Filosofia, Curitiba, v. 17 n.20, p. 165-184, jan./jun. 2005. 
dualidade da psicanálise torna-se clara: enquanto, para Politzer, o método psicanalítico dispensa o mito do teatro interior por centrar-se sobre os atos do sujeito e as interpretações do analista, a teoria freudiana reintroduz a noção de vida interior por meio do conceito de inconsciente, já que este é apresentado como um sistema psíquico, dotado de vida própria, determinando os atos do sujeito à revelia da consciência. Ou seja, o conceito de inconsciente traz para o cerne da psicanálise o mito do teatro interior que a prática freudiana havia expulsado.

O quarto pressuposto - o psíquico resulta de processos - é rompido pela técnica psicanalítica, embora se mantenha nas teorizações metapsicológicas. Enquanto no procedimento clínico freudiano o psíquico é apresentado como conseqüência de atos de um sujeito concreto história individual, acontecimentos traumáticos e organização familiar e edípica - na metapsicologia deparamo-nos com explicações que recorrem a conceitos tais como repressão, sublimação, etc. - ou seja, conceitos que se referem a processos internos ao sujeito. $\mathrm{O}$ caráter inovador da psicanálise ancora-se na construção de um novo método de abordagem, método este não introspectivo: a associação livre. Em sua técnica clínica, Freud não tem necessidade de recorrer a processos internos para abordar o fato psicológico, possibilitando que o sujeito tome o primeiro plano.

O quinto pressuposto da psicologia clássica - o significado é anterior ao relato - mantém-se na psicanálise pela noção de saber inconsciente. Os conteúdos latentes, grupos mnemônicos não disponíveis à consciência, constituem esse saber; ou seja, existem lembranças que estão ausentes do relato do paciente, por estarem 'arquivadas' no inconsciente. A crença de que o conteúdo - inconsciente ou latente - preexiste ao relato, baseia-se na idéia de que há uma significação verdadeira a ser descoberta sob a narrativa. É justamente esse último pressuposto que nos interessa discutir neste artigo, pois é a anterioridade do significado que mantém na teoria freudiana uma suposição de temporalidade e significação que se distingue radicalmente da proposta lacaniana.

O pressuposto da psicologia clássica que toma a anterioridade do significado em relação ao relato se apresenta em alguns momentos da teorização freudiana para construção de uma metapsicologia, mais especificamente quando Freud diferencia conteúdo latente e conteúdo manifesto. A importância para Politzer de refutar tal postulado deve-se ao realismo e à abstração implicados por ele. A abstração, nesse caso, con-

Revista de Filosofia, Curitiba, v. 17 n.20, p. 165-184, jan./jun. 2005. 
siste no desconhecimento da individualidade do relato e sua significação; ou, melhor dito, na crença de que a presença de que uma dada significação no aqui e agora do sujeito nada mais é do que a reprodução de uma significação geral que se manifesta na individualidade. Como conseqüência, a significação individual consiste apenas no modo como um fato psicológico é vivenciado pelo sujeito - a ênfase recai sobre a vivência específica de um fenômeno psíquico geral.

Já o realismo surge em relação ao uso do desdobramento do conteúdo: a significação convencional é desdobrada para o interior do sujeito - aí vemos a crença no teatro interior, apresentado no terceiro postulado - e substancializada. Embora na prática clínica freudiana 0 relato não seja considerado como a descrição de um estado interno, mas como a possibilidade de produzir uma significação esclarecedora do comportamento humano daquele sujeito particular, a problemática se (re)apresenta nas teorizações metapsicológicas, nas quais as representações mostram certo realismo. Tomemos o caso dos sonhos: o realismo se dá a ver por um lado, como dissociação de relato significativo, criando um duplo 'ontologizado' e, por outro, como suposição de um relato que não foi dado efetivamente pelo sujeito. Temos como exemplo, no primeiro caso, o relato do sonho e o sonho em si, revelado pela interpretação, e no segundo caso, o conteúdo latente tomado como texto. Em ambos os casos, a anterioridade da significação está colocada.

Ora, a prática clínica não pode ser desvinculada dos pressupostos teóricos sobre os quais se apóia para definir e delimitar seu campo. Desse modo, embora a clínica freudiana - e, mais especificamente, 0 método de associação livre - não necessite, em dados momentos, supor uma anterioridade do significado, a metapsicologia - base teórica para uma prática clínica - justifica as intervenções do analista por meio de seus pressupostos, entre os quais se destaca a diferenciação entre conteúdo latente e conteúdo manifesto. Como conseqüência, se constrói a ilusão de que o desdobramento do relato traz algo novo, um segundo relato mais profundo e prévio ao enunciado do paciente, no qual as intenções significativas não estão disfarçadas e surgem com seus signos adequados. Ao analista caberia refazer o percurso significativo do relato manifesto, visando alcançar o relato latente e já existente intencionalmente, atualizando-o no momento da análise.

Por meio dos pressupostos apresentados, Politzer pretende submeter a exame a estrutura teórica criada por Freud buscando averiguar

Revista de Filosofia, Curitiba, v. 17 n.20, p. 165-184, jan./jun. 2005. 
os traços de psicologia concreta contidos na psicanálise. Em sua análise, considera que há uma grande distância entre a teoria presente na metapsicologia e a teoria embutida na prática clínica, pois enquanto a primeira parece receber maior influência da psicologia clássica, a segunda antecipa uma visão concreta do homem. Dentre os diversos conceitos presentes na metapsicologia freudiana é justamente o conceito de inconsciente que, segundo Politzer, se mostra devedor da forma clássica de pensar o sujeito humano: forma que retira do agente sua condição singular e reenvia o comportamento humano ao campo das abstrações. Como conseqüência dessa análise, Politzer propõe excluir o inconsciente do cerne da teoria psicanalítica.

A exclusão do inconsciente da teoria psicanalítica, no entanto, não é tarefa simples, pois consiste na retirada de um conceito que é freqüentemente considerado como pedra angular da teoria e que marca o caráter diferencial da psicanálise em relação a outras teorias do psiquismo. Apesar da dificuldade da tarefa, Lacan parece ter tentado atender a indicação politzeriana, pois nos textos anteriores a 1953 não fez uso do conceito senão de forma adjetiva ou adverbial, resguardando para ele um papel secundário em sua argumentação - Lacan chega mesmo a apresentar o conceito de inconsciente como "uma noção inerte e impensável" (Lacan, 1998). Após o encontro com a antropologia de LéviStrauss, o movimento lacaniano consistirá em manter o conceito, modificando-o. Em sua nova conceituação, o inconsciente surgirá desvinculado dos pressupostos da psicologia clássica expostos por Politzer.

\section{O encontro com Lévi-Strauss}

O encontro com a antropologia estrutural de Lévi-Strauss permitiu a Lacan construir um conceito de inconsciente que escapa às críticas formuladas por Politzer. Tomarei dois ensaios de Lévi-Strauss a fim de mostrar os elementos que seu pensamento oferece para a argumentação lacaniana: A Eficácia Simbólica (1949) e Introduction a l'Oeuvre de Marcel Mauss (1950).

Lévi-Strauss nomeia como eficácia simbólica a construção de um mito, seja individual ou coletivo, que produz efeitos sobre o paciente. Ao tomar como modelo o trabalho realizado por um xamã da América do Sul - que reduz o sofrimento do paciente em situações de parto 
por meio da criação de uma narrativa mítica - Lévi-Strauss reflete sobre o tratamento psicanalítico. Se no primeiro caso trata-se de uma narrativa composta de elementos da comunidade social e proferida pelo xamã, na qual estão inseridos tanto o paciente quanto o curandeiro, na cura psicanalítica esta narrativa é individualizada e proferida pelo próprio sujeito. A diferença entre os dois métodos estaria na origem do mito: (1) encontrado na psicanálise como tesouro individual ou (2) recebido da tradição coletiva, no caso do xamanismo.

Pensar a psicanálise como uma prática de eficácia simbólica permite ao analista tomar a palavra em seu sentido criador, de modo a reduzir a importância da realidade ou da verdade factual. Embora isso possa parecer problemático para um analista freudiano, o qual supõe que o relato do paciente deve ter, senão um fato verídico que o sustente, pelo menos um dado de realidade segundo o qual o paciente constrói sua fantasia, o que interessa a Lévi-Strauss argumentar é a eficácia simbólica da narrativa, a qual coloca em segundo plano a veracidade dos fatos.

Não pomos os fatos em dúvida. O que é necessário indagar é se o valor terapêutico da cura se deve ao caráter real das situações rememoradas, ou se o poder traumatizante destas situações não provém do fato de que, no momento em que se apresentam, o sujeito as experimenta imediatamente sob forma de mito vivido. Com isto, entendemos que o poder traumatizante de uma situação qualquer não pode resultar de seus caracteres intrínsecos, mas da aptidão de certos acontecimentos, que surgem num contexto psicológico, histórico e social apropriado para induzir uma cristalização afetiva, que se faz no molde de uma estrutura preexistente. Em relação ao acontecimento ou à particularidade histórica, essas estruturas - ou, mais exatamente, essas leis de estrutura - são verdadeiramente intemporais. No psicopata, toda a vida psíquica e todas as experiências ulteriores se organizam em função de uma estrutura exclusiva ou predominante, sob a ação catalítica de um mito inicial; mas esta estrutura, e as outras que nele são relegadas a um lugar subalterno, se encontram também no homem normal, primitivo ou civilizado. O conjunto dessas estruturas formaria o que denominamos de inconsciente. (LÉVI-STRAUSS, 1996).

A definição lévi-straussiana de inconsciente, tal como apresentada acima, fornece a Lacan os elementos básicos - articulação entre ordem simbólica, linguagem e inconsciente - para uma nova abordagem do conceito na qual (1) não é necessária qualquer vinculação a uma

Revista de Filosofia, Curitiba, v. 17 n.20, p. 165-184, jan./jun. 2005. 
realidade efetivamente vivida pelo paciente, (2) a construção da narrativa do paciente permite organizar e contextualizar sua vivências numa perspectiva psicológica, histórica e social e (3) a temporalidade da narrativa não está associada à temporalidade dos eventos, de modo que não se trata de uma significação prévia ocorrida no momento da vivência, mas da construção a posteriori do sentido no mito individual.

A apresentação feita por Lévi-Strauss da obra de Marcel Mauss complementa a definição de inconsciente inspiradora da concepção lacaniana ao direcionar a discussão para uma contribuição contínua entre o social e o individual/psíquico, de tal forma que "toda interpretação deve fazer coincidir a objetividade da análise histórica ou comparativa com a subjetividade da experiência vivida" (Lévi-Strauss, 1968). O inconsciente surge, pois, como a noção na qual objetivo e subjetivo se encontram, de tal modo que pode fornecer o caráter comum dos fatos sociais e funcionar como elemento mediador entre o eu e o outro.

De fato, não se trata de traduzir em símbolos um dado extrínseco, mas de reduzir a sua natureza de sistema simbólico as coisas que não escapam senão por se incomunicabilizar. Como a linguagem, o social é uma realidade autônoma (a mesma, aliás); os símbolos são mais reais do que o que eles simbolizam, o significante precede e determina o significado. (LÉVI-STRAUSS, 1968).

Não se trata, portanto, de duas realidades distintas, em que uma seria mais profunda ou verdadeira, ou uma versão interior de uma realidade exterior. Ao apresentar a linguagem como uma realidade autônoma e ao recorrer à distinção entre significante e significado, Lévi-Strauss desconsidera o aspecto comunicacional da linguagem, destacando seu caráter simbólico, pois, se pensarmos a linguagem como instrumental, mera comunicação de conteúdo, a realidade será reduplicada entre realidade vivida e realidade narrada. Mas se tomarmos a linguagem em seu aspecto construtivo/simbólico, teremos a possibilidade de utilizá-la como dado objetivo, concreto, desvinculando o psíquico de sua tradicional associação com a noção de interioridade. Ou seja, a própria concepção de linguagem, vinculada ao conceito de inconsciente, permitirá a Lacan uma nova abordagem.

Revista de Filosofia, Curitiba, v. 17 n.20, p. 165-184, jan./jun. 2005. 
Inconsciente e linguagem

O marco inicial do movimento lacaniano em direção à constituição de um conceito de inconsciente articulado como linguagem data de 1953. Trata-se do Discurso de Roma, texto que tem o valor de manifesto de incitação a uma nova prática clínica, calcada em elementos concretos. Essa articulação entre psicanálise e linguagem - devedora das argumentações de Lévi-Strauss - possibilita a Lacan apresentar um conceito de inconsciente que rompe com a formulação freudiana de um aparelho mental composto de diversas instâncias psíquicas e suas conseqüentes aporias: espacialização e interioridade. Na argumentação lacaniana 0 inconsciente é apresentado como "a parte do discurso concreto, como transindividual, que falta à disposição do sujeito para restabelecer a continuidade de seu discurso consciente" (LACAN, 1998). Por ser articulado ao discurso, o inconsciente lacaniano não tem relação com as noções de interioridade ou individualidade. "O que ensinamos o sujeito a reconhecer como seu inconsciente é sua história (...)” (LACAN, 1998). Ao instigar os psicanalistas a trabalharem com o discurso do paciente, afastando-se do campo dos sentimentos, da contratransferência ou das suposições, Lacan tem como intenção constituir uma prática clínica que tome de forma objetiva a fala do paciente.

A importância do relato do paciente na prática clínica lacaniana deve-se à sua relação com o objeto próprio a uma psicanálise que não se apóie sobre a noção de interioridade, já que não se trata, como já dissemos anteriormente, do relato como uma prática de introspecção, mas de um modo de representação subjetiva. Ao tomar como apoio a argumentação de Lévi-Strauss, Lacan pode defender que a dimensão humana é da ordem do símbolo, pois o simbólico se constitui ao sobrepor o reino da cultura e da linguagem ao reino da natureza, condição especificamente humana. É importante ressaltar que o símbolo não se apresenta para Lacan como condição da existência de um universo de linguagem, mas como conseqüência deste. Por sua vez, a construção da cultura se apóia sobre um princípio organizador arbitrário, uma lei imperativa em suas formas, mas inconsciente em sua estrutura. Basta apenas mais um passo para que Lacan defenda a hipótese de que a linguagem tem forma de lei.

Se uma primeira articulação com a linguagem permite a Lacan desvincular 0 inconsciente da noção de interioridade, a constituição de uma relação entre lei, linguagem e simbólico possibilita pensar o homem

Revista de Filosofia, Curitiba, v. 17 n.20, p. 165-184, jan./jun. 2005. 
como fruto de um sistema que o ultrapassa e o determina, sistema este que se apresenta em sua fala, pois cada sujeito é simultaneamente agente e objeto de sua narrativa. O inconsciente inscreve-se dessa forma como o desconhecimento pelo sujeito da dimensão significante. Se ao falar, o sujeito supõe ser mestre do que diz, a equivocidade discursiva permite que, em sua explicitação, esse discurso diga mais do que o sujeito pretende dizer. Como conseqüência, a fala apresenta-se como instrumento privilegiado da prática analítica ao exibir em seu desenrolar a estrutura simbólica que funda o humano e os princípios que o determinam. Não se trata, pois, de uma relação de compreensão entre paciente e analista, mas de uma relação ternária: falante, discurso, analista, na qual o discurso se apresenta como um critério objetivo.

Além de visar a objetividade da prática clínica, Lacan, em sua conceituação de inconsciente, busca situá-lo em um sistema de oposições - tomado de empréstimo à teoria saussuriana do signo lingüístico que evita qualquer suposição de substancialidade do inconsciente.

Por um lado, o inconsciente é, como acabo de defini-lo, alguma coisa de negativo, de idealmente inacessível. Por outro lado, é algo de quase real. Enfim, é algo que será realizado no simbólico ou, mais exatamente, que, graças ao progresso simbólico na análise, terá sido. Eu lhes mostrarei, segundo os textos de Freud, que a noção de inconsciente deve satisfazer esses três termos (LACAN, 1983).

Dentre os três termos em jogo - negatividade do inconsciente, seu caráter concreto e sua realização no simbólico - é justamente o último que abrirá caminho para a teorização lacaniana em torno da temporalidade. Segundo Lacan, o tempo verbal do inconsciente é o futuro anterior, tempo que aponta para a dimensão de não-realizado, aquilo que poderia vir a ser, mas ainda não se realizou.

O passado e o futuro precisamente se correspondem. E não é em qualquer sentido - não no sentido que vocês poderiam acreditar que a análise indica, a saber, do passado ao futuro. Ao contrário, na análise, justamente porque a técnica é eficaz, isso caminha na boa ordem - do futuro ao passado (1986).

Como conseqüência dessa concepção temporal do inconsciente, a volta do recalcado pode ser apresentada na teoria lacaniana como 
vinda do futuro e não do passado. Dando continuidade a sua argumentação a favor da articulação entre inconsciente e linguagem, Lacan afirma:

Quando fala do inconsciente, Freud não nos diz que ele é estruturado de uma certa maneira, mas, ainda assim, diz ele isso, na medida em que as leis que propõe, as leis de composição desse inconsciente, coincidem exatamente com algumas das mais fundamentais leis de composição do discurso. Por outro lado, no modo de articulação que é próprio do inconsciente, falta toda sorte de elementos que estão implicados em nosso discurso comum (...) (1999).

Podemos assinalar que, cada vez mais, a teoria lacaniana relaciona inconsciente e linguagem de modo a realizar seu intento inicial: criar uma nova conceituação de inconsciente. Esta articulação possibilita uma saída do impasse freudiano - com toda a problemática decorrente dessa concepção - de representação do inconsciente como uma instância interna ao sujeito. O recurso à linguagem permite conceber o inconsciente de modo dessubstancializado.

A articulação dos fenômenos analíticos com a linguagem, como estrutura, permite tomar a dimensão inconsciente, por um lado, no campo dos significantes e a consciência, por outro, no campo das significações, o que, em sua argumentação visa a apresentar os traços inconscientes como marcas que não trazem uma significação já dada. A Bewusstsein é da ordem de lembranças conceituais. A noção de relação causal aparece ali pela primeira vez como tal. É o momento em que o significante, uma vez constituído, ordena-se secundariamente a alguma outra coisa, que é a aparição do significado (LACAN 1988).

Nessa perspectiva, a significação só se faz num momento posterior. Os traços inconscientes, por não terem uma significação prévia, surgem como desvinculados da idéia de uma memória inconsciente. Tal qual a noção de temporalidade retroativa, a concepção de significante possibilita tomar a fala do sujeito como construtora de sentido a cada momento de sua enunciação. A correlação entre inconsciente e significante permite não apenas apontar a possibilidade de surgimento de novos sentidos, mas também colocar em primeiro plano a referência ao contexto concreto de articulação do paciente, já que não se trata de sentidos que estejam presentes ali, mas dos sentidos que poderão surgir pela oposição dos diferentes termos significantes.

Revista de Filosofia, Curitiba, v. 17 n.20, p. 165-184, jan./jun. 2005. 
Ao considerar os significantes como elementos sem vínculo direto com o significado e que tomam seu valor em oposição a todos os outros elementos, produz-se uma alteração radical da questão da significação. A ação nachträglich do significante pode, portanto, ser relacionada com a temporalidade do inconsciente, já que esta, segundo Lacan, se organiza a posteriori em um tempo verbal - futuro anterior - que possibilita ressignificar o passado. Desse modo, as formações do inconsciente podem ser apresentadas como efeitos de sentido segundo combinações significantes. Ou seja, a argumentação lacaniana permite tomar as combinações significantes como geradoras de sentido que escapam ao sujeito sem recorrer à suposta intencionalidade de uma instância psíquica.

(...) no decorrer de um discurso intencional em que o sujeito se apresenta como querendo dizer alguma coisa, produz-se algo que ultrapassa seu querer, que se manifesta como um acidente, um paradoxo, ou até um escândalo. Mas, nas condições em que se produz esse acidente, verifica-se que ele é registrado e valonizado na categoria do fenômeno significativo de engendramento de um sentido (LACAN, 1999)

Como conseqüência dessa acepção, o inconsciente é apresentado na teoria lacaniana como tropeço significante, desvinculando-o da idéia de um depósito de memórias inconscientes. Ou seja, é pelo valor de significação ou, dito de outra forma, pela atribuição de um sentido à falha discursiva, que o sujeito constitui o inconsciente, cuja articulação significativa é construída no momento de sua enunciação, por meio da suposição de sentido construída sobre a equivocidade significante. Não se trata, pois, de um significado já dado e oculto à consciência do paciente.

O inconsciente, desvinculado da noção de espaço psíquico, é apresentado como um saber disjunto do corpo de conhecimento consciente do sujeito, um ato de enunciação que implica simultaneamente perda e produção de sentido. Desse modo, a autonomia da dimensão significante em relação ao campo do sentido inviabiliza a noção de intencionalidade inconsciente, pois não se trata de uma entidade que espera o momento para se manifestar ou que quer dizer algo específico, mas é o próprio exercício do significante que evoca a ordem do inconsciente. Dito de modo mais claro, o equívoco de sentido presente em qualquer enunciação produz um desconhecimento discursivo do sujeito em relação a sua fala, uma impossibilidade de reconhecimento de sua enunciação simbólica.

Revista de Filosofia, Curitiba, v. 17 n.20, p. 165-184, jan./jun. 2005. 
É justamente a autonomia da dimensão significante que dá à prática analítica lacaniana seu diferencial em relação ao modelo freudiano. O trabalho analítico, na perspectiva de Lacan, permite que o sujeito, ao falar, construa uma cadeia significante, um saber - ressaltemos aqui o termo 'construção' - sobre suas crenças particulares. No entanto, ocorre, de forma paralela à intencionalidade da significação de seu relato, a produção de equívocos de sentido. Diferentemente de Freud, não se trata da descoberta de uma verdade oculta, mas de uma construção significante que aponta a posição subjetiva de um dado paciente, posição suposta pela cadeia significante, por meio da qual o sujeito se representa. Dessa forma, mentir, enganar ou dizer a verdade, no contexto da prática clínica lacaniana, são formas de representação da subjetividade daquele sujeito particular. Não se trata de buscar uma intencionalidade, mas de ler os efeitos que uma dada estrutura discursiva implica em termos de posição subjetiva.

A conceituação do inconsciente como ignorância discursiva dizer mais do que pretende e menos do que supõe - não mais nos permite perguntar sobre a localização do inconsciente quando este não está presente. $\mathrm{O}$ inconsciente só pode ser percebido pelos seus efeitos, efeitos de desconhecimento do sujeito em relação a seu discurso. Na clínica, isso é facilmente apreendido: se a consciência nos dá o sentimento de eu (moi) no discurso, na situação analítica, o sujeito confronta-se com o desconhecimento sistemático na sua própria produção discursiva. Devido às intervenções do analista, o sujeito se reconhece mais além do conhecimento consciente, pois se articula em uma ordem simbólica, a cadeia significante. Ou seja, o que é articulado na cadeia significante não é articulável na dimensão de sujeito instituído pela palavra - o inconsciente é da ordem desse não articulável na fala do sujeito.

\section{Considerações finais}

A articulação entre inconsciente e linguagem proposta por Lacan traz consideráveis modificações para a prática analítica, bem como soluciona algumas aporias da teoria freudiana. Neste artigo, busquei apresentar os impasses da metapsicologia e da teoria da clínica freudiana por meio das críticas formuladas por Politzer, mais

Revista de Filosofia, Curitiba, v. 17 n.20, p. 165-184, jan./jun. 2005. 
especificamente em relação ao pressuposto da anterioridade do significado. A fim de ilustrar as conseqüências de uma psicanálise que tome o significado como anterior ao relato, detive-me sobre dois aspectos: (1) a temporalidade inconsciente e (2) a significação da narrativa.

Na teoria freudiana, a temporalidade do inconsciente é associada ao tempo verbal do pretérito perfeito, devido à articulação entre inconsciente e memória. Como conseqüência, em sua prática clínica, o analista freudiano necessita preocupar-se com a descoberta de traços gravados quando do momento da inscrição de uma dada vivência, bem como com a correlação entre o fantasiado e 0 vivido. Por sua vez, o paciente em análise parece buscar, por meio de sua narrativa, a revelação de um passado oculto à consciência, porém preservado, tal como um objeto arqueológico. Ao articular inconsciente e linguagem, Lacan possibilita uma desvinculação entre inconsciente e memória e, poderíamos mesmo dizer, desconsidera a idéia de um aparelho psíquico composto por sistemas, dentre os quais encontraríamos o inconsciente. $\mathrm{O}$ inconsciente nada mais é do que um tropeço significante, o desconhecimento do sujeito das determinações significantes que o guiam. Sem substância ou localização, o inconsciente lacaniano permite situar uma prática clínica que se apóia na concepção de temporalidade não-realizada, tempo verbal do futuro anterior, cuja efetivação se daria no momento do relato. Ao analista caberia apontar as equivocidades significantes que se apresentam na fala do paciente e os efeitos de sentido que se constituem nesta escolha de um dado enunciado, destacando o caráter de enunciação, de responsabilidade subjetiva do agente sobre sua fala.

Após Lacan, o inconsciente não é mais uma instância interna ao sujeito, que o determina à sua revelia, mas tão somente um jogo combinatório operando em sua espontaneidade, cujo modelo é a linguagem. Pensar o inconsciente estruturado como linguagem institui uma modificação conceitual que implica em um novo modelo clínico, o qual subverte a relação entre temporalidade e significação. 
Referências

FREUD, Sigmund. Obras completas psicológicas de Sigmund Freud. Edição Standard Brasileira. Rio de Janeiro, RJ: Imago, 1980. rortu, 1992.

Obras completas de Sigmund Freud. Buenos Aires: AmorGABBI JR., Osmyr. É possível uma clínica psicanalítica sem metapsicologia? Psicologia Clínica, Rio de Janeiro, v. 12, n.1, 2000.

. A eterna juventude da psicologia: o caso da psicanálise. In: POLITZER, G.

Crítica dos fundamentos da psicologia: a psicologia e a psicanálise. Piracicaba: Editora da UNIMEP, 1998.

LACAN, J . Escritos. Rio de Janeiro, RJ: Jorge Zahar, 1998.

. Seminário, Livro 1: os escritos técnicos de Freud. Rio de Janeiro, RJ: Jorge Zahar, 1983. Publicada originalmente em 1953/ 1954.

- Seminário, Livro 3: as psicoses. Rio de Janeiro, RJ: Jorge Zahar, 1988. Publicado originalmente em 1955/1956.

. Seminário, Livro 5: as formações do inconsciente. Rio de Janeiro, RJ: Jorge Zahar, 1999. Publicado originalmente em 1957/ 1958.

. Seminário, Livro11: os quatro conceitos fundamentais da psicanálise. Rio de Janeiro, RJ: Jorge Zahar, 1990. Publicado originalmente em 1964.

LÉVI-STRAUSS, Claude. Antropologia Estrutural. Rio de Janeiro, RJ: Tempo Brasileiro, 1996.

. Introduction a l'O euvre de Marcel Mauss. In: MAUSS, Marcel. Sociologie et anthropologie. Paris: PUF, 1968.

MILNER, J-C. Le Périple Structural: figures et paradigme. Paris: Seuil, 2002.

Revista de Filosofia, Curitiba, v. 17 n.20, p. 165-184, jan./jun. 2005. 
POLITZER, Georges. Crítica dos fundamentos da psicologia: a psicologia e a psicanálise. Piracicaba: Editora da UNIMEP, 1998. 1969.

. Écrits 2: les fondements de la psychologie. Paris: Sociales, SAUSSURE, F. Curso de lingüística geral. São Paulo, SP: Cultrix, 1995.

Recebido em: Received in: 14/02/ 2005 Aprovado em: Approved in: 31/ 03/2005 